\title{
The Correlation between Serum Growth Differentiation Factor-15 Levels and Post-Acute Myocardial Infarction Acute Heart Failure
}

\author{
Kenny Mayavani, JB Suparyatmo, Dian Ariningrum \\ Department of Clinical Pathology, Faculty of Medicine, Sebelas Maret University/Dr. Moewardi Hospital, Surakarta, Indonesia. \\ E-mail: kenny.maya1234@gmail.com
}

\begin{abstract}
Acute Heart Failure (AHF) is a common rapid complication of Acute Myocardial Infarction (AMI). Myocardial dysfunction leads to pathologic remodeling of the heart, which causes AHF. Growth differentiation factor-15 (GDF-15) is expressed by cardiomyocytes and upregulated due to injury and cardiomyocyte damage. Thus, it can be used as a predictor of severe heart damage. This study aimed to determine the correlation between GDF-15 levels and the incidence rate of post-AMI AHF. This prospective cohort study was performed in patients with AMI treated in Dr. Moewardi Hospital from August to September 2019. The Kolmogorov-Smirnov normality test was used. Bivariate analysis was applied for Hazard Ratio (HR) with $95 \%$ CI. The GDF-15 cut-off used the ROC curve. The Cox Regression Proportional Hazard Model was used for multivariable analysis. The significance value was $p<0.05$. During the study, there were a total of 74 subjects. Bivariate analysis showed significant correlation between serum GDF-15 levels and hypertension history to the incidence of post-AMI AHF [HR=3.259; $95 \% \mathrm{CI}$ (1.1558-6.819); $p=0.002]$ and [HR=3.293; 95\%CI (1.489-7.282); $p=0.003]$. Multivariate analysis showed that both variables had a similar strength of the correlation. The risk and the incidence rate of AHF were three times higher in AMI subjects with a history of hypertension and elevated GDF-15 levels. High serum GDF-15 levels and a history of hypertension can be predictors of post-AMI AHF.
\end{abstract}

Keywords: Acute myocardial infarction, GDF-15, hypertension history, acute heart failure

\section{INTRODUCTION}

Acute Myocardial Infarction (AMI) is a disease caused by a sudden decrease in coronary blood flow. It causes cardiomyocyte necrosis due to a block by atherosclerotic plaque. ${ }^{1,2}$ The diagnosis is based on clinical evaluation, electrocardiography (ECG), biochemical examination, invasive and non-invasive imaging. ${ }^{3}$ The recommended biomarker for AMI diagnostics is cardiac troponin I (cTnI) due to its high sensitivity and specificity for myocardial injury. ${ }^{4}$

In Indonesia, Coronary Heart Disease (CHD) is a cardiovascular disease with the highest prevalence of $1.5 \%$ and the second-highest cause of death after stroke (12.9\%). ${ }^{5,6}$ Acute Heart Failure (AHF) is a group of symptoms and clinical signs including shortness of breath at rest or activity, fatigue, edema of the limbs, tachycardia, tachypnea, pulmonary irritation, pleural effusion, increased jugular venous pressure, peripheral edema, and hepatomegaly accompanied by objective signs of structural and functional disorders of the heart that occurs in a short time, which requires immediate management and occurs at the first time (de novo). ${ }^{7.8}$ Acute myocardial infarction is one of the causes of AHF complications with a quite high incidence ranging from $14 \%-36 \%{ }^{9}$

The term "remodeling" is a cellular, molecular, and interstitial change with clinical manifestations of changes in size, shape, and function (dilatation, spheres, thickening of the heart wall) of cardiomyocytes and other heart cells due to cardiac infarction or injury. The process of cardiac remodeling is categorized into two types, namely, physiological and pathological remodeling. This remodeling process is the most potent prognosis factor in post-AMI patients. ${ }^{10}$

The healing process with post-AMI ventricular remodeling is divided into three phases: the inflammatory phase, the proliferative phase, and the maturation phase. ${ }^{11,12}$ Pump failure with pathological remodeling accompanied by signs of Heart Failure (HF) is an acute or subacute phase complication which occurs within a few days. ${ }^{8}$

Immediate measurement of biomarkers after AMI can provide early information on the severity of AMI and the risk of AMI complications, thus providing a clue for appropriate individual management. Prognostic biomarkers that have been known and are believed to be predictors of HF in AMI patients are $\mathrm{B}$-type natriuretic peptide (BNP) and $\mathrm{N}$-terminal 
pro-BNP (NT-proBNP). However, these biomarkers have a very short half-life (20 minutes for BNP and 1-2 hours for NT-pro BNP). Also, its levels decrease in obesity due to activated receptor clearance and the degradation process of natriuretic peptide. ${ }^{13}$

Several novel biomarkers such as growth differentiation factor-15 (GDF-15), suppression of tumourigenesis 2 (ST2), and galectin-3 are currently being developed, but have not been much studied. ${ }^{14,15}$ Growth differentiation factor- 15 is a cytokine protein that is responsive to stress in the form of tissue injury and belongs to the TGF- $\beta$ family. Cardiomyocytes release these cytokines as cardioprotection through anti-inflammatory, antihypertrophic, and antiapoptotic effects on the presence of cardiac injury. ${ }^{16}$

Another opinion suggests that elevated serum GDF-15 levels have epiphenomenon properties (have opposite effects on specific organs in a disease). ${ }^{17}$ Increased levels are associated with the progression and mortality of cardiovascular disease. $^{18}$

Based on the theory and previous studies that are still contradictory between the role of GDF-15 as cardioprotective and elevated levels associated with a poor prognosis in AMI, this study was performed to determine the correlation between GDF-15 biomarkers and AHF in AMI.

\section{METHODS}

This study was an observational analytic study with a prospective cohort approach to determine the correlation of serum GDF-15 levels with the incidence of post-AMI AHF. The accessible population of this study was adult patients aged $\geq 18$ years with a new diagnosis of AMI established by clinicians, according to Perhimpunan Dokter Spesialis Kardiovaskular Indonesia (PERKI), being treated at Dr. Moewardi Hospital, Surakarta in August-September 2019, then observed during treatment whether clinicians diagnosed AHF according to clinical criteria and objective findings. Exclusion criteria were patients with a history of another heart disease, impaired renal function based on medical history and eGFR reduction $<60 \mathrm{~mL} / \mathrm{min}$ $/ 1.73 \mathrm{~m}^{2}$, an impaired liver function characterized by SGOT/ALT level > two times upper limit range and history of hepatitis based on hepatitis surface antigen ( $\mathrm{HBsAg}$ ) and positive result of hepatitis $\mathrm{C}$ virus (anti-HCV) antibodies, and malignancy based on the medical history.

This research has independent and dependent variables. The independent variables in this study were serum GDF-15 levels, age, gender, history of DM, history of hypertension, obesity status, and hs-troponin I. Dependent variables were symptoms of AHF events characterized by shortness of breath, pulmonary edema, $\mathrm{X}$-ray of the heart enlargement and decreased Ejection Fraction (EF) (<50\%) diagnosed by clinicians. Serum hs-cTnI and GDF-15 levels measurement were carried out in the laboratory, and any AHF events were then observed during treatment.

Precision tests within a day preceded laboratory tests; therefore, the quality of test results can be accounted for. Data on the essential characteristics of research subjects and research variables were expressed in $n(\%)$ using the Chi-Square test, mean \pm Standard Deviation (SD), or median (range) with the Kolmogorov-Smirnov normality test. The AHF and non-AHF groups were compared using the unpaired T-test for normally distributed data and the Mann-Whitney $U$ test for abnormally distributed data.

Bivariate analysis was performed to determine the correlation between independent variables (gender, age, history of hypertension, history of DM, hs-troponin I levels, serum GDF-15 levels) and AHF using $2 \times 2$ test tables, and HR was determined with 95\% CI using survival analysis bivariate Cox Regression. The $p$-value $<0.05$ was significant. The cut-off parameters of GDF-15 and hs-cTnI was obtained from the ROC and AUC curves. The p-value was significant if $<0.05$ and $95 \% \mathrm{CI}$ did not exceed number one.

Multivariate analysis was performed with the significance value of bivariate analysis was $p<0.25$. The investigation was begun with a survival analysis using the Kaplan-Meier curve. The survival equation analysis of the Cox Regression Proportional Hazard Model was carried out to determine the order of the strength of the relationship between the independent variables and search for $\mathrm{HR}$; $95 \% \mathrm{CI}$, hazard function, and survival function probability of occurrence of AHF. Statistical analysis was carried out using a computer system.

Research permission was obtained from the Health Research Ethics Committee of the Faculty of Medicine, Sebelas Maret University/Dr. Moewardi, Surakarta, with number 918/VII/HREC/2019.

\section{RESULT AND DISCUSSION}

The study involved 74 patients diagnosed with AMI by clinicians treated at Surakarta RSDM from August to September 2019.

The primary characteristics of subjects were 
divided into groups of AHF and without AHF. This study included 74 patients with a clinical diagnosis of AMI by clinicians, 35 (47.3\%) subjects with complications of AHF in treatment, and 39 (52.7\%) subjects without complications of AHF.

The research subjects consisted of 59 male (79.7\%) and 15 (20.3\%) female subjects. The proportion of male subjects with AHF complications was higher (49.2\%) than that of females $(40.0 \%)$ despite statistical insignificance.

The mean age in the AHF group was $57.7 \pm 10.8$ years. This result was different from the study of Auffret et al., and Wellings et al. found that the prevalence of AHF complications in AMI was higher in females, and the median age in the study was 69 (58-79) years. ${ }^{19,20}$ This was because the median age in the 2016 survey was higher than the current research, and it was highly related to the number of male subjects in this study. Schoenenberger et al. suggests that males and menopause female are at a higher risk of cardiovascular disease than females who have not reached menopause, this is related to the protective effect of the female estradiol hormone at the reproductive age. ${ }^{21}$

There were 3 (4.1\%) patients with death outcomes during hospitalization, and all of them were with post-AMI AHF (8.5\%). The first subject experienced AHF on the first day of treatment died within 24 hours of hospitalization with GDF-15 levels of $1078 \mathrm{pg} / \mathrm{mL}$. On the first day, the second subject experienced AHF died on the fourth day with GDF-15 levels of $1426.6 \mathrm{pg} / \mathrm{mL}$. On the first day, the third subject experienced AHF died on day 11 with GDF-15 levels of $1038.2 \mathrm{pg} / \mathrm{mL}$.

Bivariate analysis showed $95 \% \mathrm{HR}$ and CI results for gender, age, history of DM, history of hypertension, obesity, serum hs-CTnI, and GDF-15 levels respectively [1.204 $(0.500-2.900) ; p=0.679]$, [0.899 (0.462-1.748); $p=0.753]$, [0.855 (0.425-1.717); $p=0.659], \quad[3.293(1.489-7.282) ; p=0.003], \quad[0.917$ $(0.381-2.210) ; \quad p=0.848], \quad[0.988 \quad(0.509-1.918)$; $p=0.972$ ], [3.259 (1.558-6.819); $p=0.002$ ] (Table 1). This study found a significant correlation between history of hypertension and GDF-15 level $\geq 1068$ $\mathrm{pg} / \mathrm{mL}$ with the incidence of post-AMI AHF.

There were $42(56.8 \%)$ subjects with a history of overall hypertension in this study. There were 27 (64.3\%) and 8 (25\%) post-AMI, subjects with and without a history of hypertension. Besides, there were 15 (35.7\%) AMI subjects with a history of hypertension but without AHF complications. The results of this study were in line with research by Auffret et al. suggesting that the ratio of the history of Hypertension with AHF and without AHF was $51.3 \%: 37.7 \%(p<0.001){ }^{19}$

Hypertension is a risk factor for coronary artery disease. The pathophysiology occurs by ventricular hypertrophy, coronary endothelial and microvascular

Table 1. Characteristic of subjects and HR between independent variables with post-AMI AHF

\begin{tabular}{|c|c|c|c|c|c|}
\hline \multirow{2}{*}{ Variables (unit) } & & \multicolumn{2}{|c|}{ n (\%) } & \multirow{2}{*}{ HR $(95 \% \mathrm{CI})^{*}$} & \multirow{2}{*}{$\mathbf{P}$} \\
\hline & & AHF & without AHF & & \\
\hline \multirow[t]{2}{*}{ Gender } & Male & $29(49.2)$ & $30(50.8)$ & $1.204(0.500-2.900)$ & 0.679 \\
\hline & Female & $6(40.0)$ & $9(60.0)$ & & \\
\hline \multirow[t]{2}{*}{ Age (years old) } & $\geq 56$ & $19(44.2)$ & $24(55.8)$ & $0.899(0.462-1.748)$ & 0.753 \\
\hline & $<56$ & 16 (51.6) & $15(48.4)$ & & \\
\hline History of type & Yes & 12 (42.9) & $16(57.1)$ & $0.855(0.425-1.717)$ & 0.659 \\
\hline 2 DM & No & $23(50.0)$ & $23(50.0)$ & & \\
\hline \multirow{4}{*}{$\begin{array}{l}\text { History of } \\
\text { hypertension } \\
\text { Obesity }\end{array}$} & Yes & $27(64.3)$ & $15(35.7)$ & $3.293(1.489-7.282)$ & 0.003 \\
\hline & No & $8(25.0)$ & $24(74.0)$ & & \\
\hline & Yes & $6(42.9)$ & $8(57.1)$ & $0.917(0.381-2.210)$ & 0.848 \\
\hline & No & $29(48.3)$ & $31(51.7)$ & & \\
\hline \multirow[t]{2}{*}{ hs-cTnI (ng/l) } & $\geq 8900$ & 18 (47.4) & $20(52.6)$ & $0.988(0.509-1.918)$ & 0.972 \\
\hline & $<8900$ & $17(47.2)$ & $19(52.8)$ & & \\
\hline \multirow[t]{2}{*}{ GDF-15 (pg/mL) } & $\geq 1068$ & $25(69.4)$ & $11(30.6)$ & $3.259(1.558-6.819)$ & 0.002 \\
\hline & $<1068$ & $10(26.3)$ & $28(73.7)$ & & \\
\hline Total & & 35 (47.3) & $39(52.7)$ & & \\
\hline
\end{tabular}

*HR was obtained using Cox Regression analysis.

Abbreviation: $\mathrm{AHF}=$ Acute Heart Failure; $\mathrm{HR}=$ Hazard Ratio; $\mathrm{CI}=$ Confidence Interval; $\mathrm{p}=$ Significance value; $\mathrm{DM}=$ Diabetes Mellitus; hs-cTnI=high sensitive cardiac troponin I; GDF-15= Growth Differentiation Factor-15 
dysfunction, and increased atherosclerosis in the coronary arteries. Severe microvascular injury between infarctions will manifest as a sudden microvascular obstruction. Still, if it occurs continuously, there will be irreversible and progressive capillary degradation leading to the expansion of the infarction zone. $^{22}$ Sympathetic Neural System (SNS) and Renin-Angiotensin-Aldosterone-System (RAAS) activation resulting in left ventricular remodeling and progressive impairment of cardiac function which contributes to the incidence of HF.7 median of serum GDF-15 levels in the AHF group were 1427 $\mathrm{pg} / \mathrm{mL}$, which is above the normal value of GDF-15 (200-1200 pg/mL).

The median level of GDF-15 in this study was similar to the finding in the study of Khan et al., which showed a median value of serum GDF-15 of 1470 $\mathrm{pg} / \mathrm{mL}^{18}$ There were 25 subjects (69.4\%) who had serum GDF-15 levels above cut-off value ( $\geq 1068$ $\mathrm{pg} / \mathrm{mL}$ ) with the incidence of post-AMI during treatment. Bivariate analysis obtained HR [3.259 (95\% CI 1.558-6.819); $p=0.002$ ].

High GDF-15 levels are associated with the incidence of post-AMI AHF during treatment, meaning that at any time during treatment, AMI patients with GDF-15 $\geq 1068 \mathrm{pg} / \mathrm{mL}$ are 3.1 times more likely to develop AHF compared to the group with GDF-15<1068 pg/mL. The figure 1068 was obtained from the ROC curve with AUC $[0.662$ (95\% $\mathrm{CI}=0.533-0.792)]$ and with the most optimal sensitivity and specificity of $71.43 \%$ and $71.79 \%$, respectively. The results of this study were lower than the study of Khan et al., which predicted death or HF post-AMI for one year, using the median level of GDF-15 as a COV of $1470 \mathrm{pg} / \mathrm{mL}$ with Area Under Curve (AUC) Receiver Operating Characteristic (ROC) results $[0.73(95 \% \mathrm{CI}=0.70-0.76)]$

The hazard ratio obtained from the study was 4.24 (95\% CI=3.21-5.62); $p<0.001] .{ }^{18}$ The differences of this study and Khan et al. were the lower range of GDF-15 levels, the time of observation and outcome, the time of inspection during treatment, and the result of AHF occurrence. Khan et al. revealed that GDF-15 levels range was quite wide (250-31860 $\mathrm{pg} / \mathrm{mL}$ ), the occurrence of death or HF was observed with two endpoints, the first was observed in one year, and while the second was observed until death, hospitalization with HF or recurrent Myocardial Infarction (MI). In other words, GDF-15 can be a biomarker predictor of the prognosis of HF events after short-term and long-term AMI.

Multivariate analysis found the similar strength of the relationship between the history of hypertension,
GDF-15, and the incidence of post-AMI AHF $[H R=2.533 ; 95 \% \quad C I=(1.119-5.734) ; p=0.025]$ and $[H R=2.554 ; 95 \% C I=(1.195-5.459) ; p=0.016]$. High GDF-15 levels accompanied by a history of hypertension increase the risk of post-AMI AHF in treatment at Dr. Moewardi Hospital, Surakarta.

This study has several limitations, including limited observation time during treatment only and no assessment of the condition after discharge. AHF onset was determined in days, preferably in hours, so that it possibly more varied for each individual. This study does not take into account both invasive therapy and other oral therapies that have been and were being carried out by patients.

\section{CONCLUSION AND SUGGESTION}

This study showed a significant correlation between high serum GDF-15 levels and the incidence of post-AMI AHF during treatment. Bivariate and multivariate analysis showed a similar strength of correlation between the prevalence of post-AMI AHF with both serum GDF-15 levels and a history of hypertension. High serum GDF-15 levels alone can be a biomarker predictor of the rate of post-AMI AHF occurrence during treatment and a history of hypertension in patients to provide more information about the probability of hazard and survival of post-AMI AHF.

Based on this study, further research was needed to evaluate the correlation of serum GDF-15 levels with the incidence of post-AMI AHF with more extended observation time, the onset of AHF within hours, and taking into account the therapy given to patients.

\section{REFERENCES}

1. Rathore V, Mahat RK. Risk factor for acute myocardial infarction: A review. EJMI, 2018; 2(1): 1-7.

2. Liu $\mathrm{S}$, Chen $\mathrm{X}$, Wang $\mathrm{H}$, Wu $\mathrm{M}$, Wang $\mathrm{Y}$, Liu $\mathrm{T}$. Association of GFD-15 and syntax score in patient with acute myocardial infarction. Hindawi Cardiovascular Therapeutics. https://doi.org/10.1155/2019/9820210. (accessed May 3, 2019).

3. Anderson JL, Morrow DA, Champion EW.(ed). Acute myocardial infarction. N Engl J Med, 2017; 376(21): 2053-64.

4. Chen Y, Tao Y, Zhang L, Xu W, Zhou X. Diagnostic and prognostic value of biomarkers in acute myocardial infarction. Postgrad Med J, 2019; 95: 210-216.

5. Badan Penelitian dan Pengembangan Kesehatan (Balitbangkes) Kementrian Kesehatan Republik Indonesia. Hasil Riset Kesehatan Dasar 2013. Jakarta, Bakti Husada, 2013; 83-97.

6. Kementrian Kesehatan Republik Indonesia (Kemenkes 
RI). Penyakit jantung penyebab kematian tertinggi, Kemenkes ingatkan CERDIK. www.depkes.go.id/ article/view/17073100005. (accessed May 29, 2019).

7. Costa DG. The pathophysiology of myocardial infarction-induced heart failure. J Pathophys, 2018; 25; 277-284.

8. Perhimpunan Dokter Spesialis Kardiovaskuler Indonesia (PERKI). Pedoman tatalaksana sindrom koroner akut. $4^{\text {th }}$ Ed., www.inaheart.org. (accessed May $17,2019)$

9. Bahit C, Kochar A, Granger CB. Post-myocardial infarction heart failure. JACC: Heart Failure, 2018; 6(3): 179-86.

10. Azevedo PS, Polegato BF, Minicucci MF, Paiva SAR, Zornoff LAM. Cardiac remodeling: Concepts, clinical impact, pathophysiological mechanisms, and pharmacologic treatment. Arq Bras Cardiol, 2015; 106(1): 62-69.

11. Frangogiannis NG. Pathophysiology of myocardial infarction. Compr Physiol, 2015; 5: 1841-1875.

12. Seropian IM, Toldo S, Tassel BWV, Abbate A. Anti-inflammatory strategies for ventricular remodeling following st-segment elevation acute myocardial infarction. J Am Coll Cardiol, 2014; 63(16): 1593-603.

13. Milks MW, Nambi V. Cardiac injury, maladaptation, and heart failure incidence. In Nambi V. (ed)., Biomarkers of cardiovascular disease. Elsevier. 2019. https://doi.org/10.1016/B978-0-323-54835-9.000089. (accessed June 22, 2019).

14. Feistritzer HJ, Klug G, Reinstadler SJ, Reindl M, Mayr A, Mair J, Metzler B. Novel biomarkers predicting cardiac function after acute myocardial infarction. BMB. 2016. http://bmb.oxfordjournals.org/ at Serials Dept/ Cornell University Medical Library on August 17, 2016. (accessed May 25, 2019)

15. Salvagno GL, Pavan C. Prognostic biomarkers in acute coronary syndrome. 2016. http://dx.doi.org/ 10.21037/atm.2016.06.36. (Accessed May 25, 2019)
16. Kempf T, Eden M, Strelau J, Naguib M, Willenbockel C, Tongers J, Heineke J, et al. The transforming growth factor- $\beta$ superfamily member growth differentiation factor-15 protects the heart from ischemia/ reperfusion injury. AhaJournals, http://circres. ahajouurnals.org. (accessed June 20, 2019).

17. Tsai WWV, Husaini Y, Sainsbury A, Brown DA, Breit SN. The MIC-1/GDF-15-GFRAL pathway in energy homeostasis: Implications for obesity cachexia, and other associated diseases. Cell metabolism Review, https://doi.org/10.1016/j.cmet.2018.07.018. (accessed June 22, 2019).

18. Khan SQ, Ng K, Dhillon O, Kelly D, Quinn P, Squire LB, Davies JE, et al. Growth differentiation factor-15 as a prognostic marker in patients with acute myocardial infarction. Eurheartj, 2009; 30:1057-65.

19. Auffret V, Leurent G, Gilard M, Hacot JP, Filippi E, Delaunay $R$, Rialan $A$, et al. Incidence, timing, predictors, and impact of acute heart failure complicating ST-segment elevation myocardial infarction in patients treated by primary percutaneous coronary intervention. International Journal of Cardiology, 2016; 221: 433-442.

20. Wellings J, Kostis JB, Sargsyan D, Cabrera J, Kostis WJ. Myocardial Infarction Data Acquisition System (MIDAS) study group. Risk factors and trends in incidence of heart failure following acute myocardial infarction. The American Journal of Cardiology, https://doi.org/10.1016/j.amjcard.2018.03.005. (accessed May 22, 2019).

21. Schoenenberger AW, Pfaff D, Dasen B, Frismantiene A, Erne $P$, Resink TJ, et al. Gender-specific associations between circulating cadherin and high molecular weight-adiponectin in patients with stable coronary artery disease. PLos One Journal, 2015; 10(6): e0131140.

22. Carrick D, Haig C, Maznyczka AM, Carberry J, Mangion K, Ahmed N, May VTY, et al. hypertension, microvascular pathology, and prognosis after an acute myocardial infarction. Hypertension, 2018; 72: 720-730. 